\title{
Research on the Development of City Financial Systems under the Rural Revitalization Strategy
}

\author{
Jilu Liu*, Qiaoyu Zhang, Xiaoming Zeng \\ Taizhou University, Taizhou, China
}

Funding: This paper is funded by the 2018 Taizhou philosophy and social science planning project "Research on city financial system construction under the background of Rural Revitalization Strategy" (fund code: 18GHD09).

\begin{abstract}
The implementation of the rural revitalization strategy can provide a better solution for problems such as the "three rural" development limitations and the imbalance of urban and rural economic development as it is the key to comprehensive building of a well-off society. Based on Linhai City's finance status, this article analyzes the financial needs of the city for a better economic development under the rural revitalization strategy which prioritizes the policy of building a city financial system. The city's financial system should be organized in a multi-level stucture for better economic development. This will improve the credit system of villages and towns, strengthen agricultural product innovation financially, and improve the finances of rural residents.
\end{abstract}

Keywords: Rural revitalization; City economy; City financial system; Linhai City

Publication date: May, 2021; Publication online: 31 May, 2021

*Corresponding author: Jilu Liu, luyis99@126.com

\section{Introduction}

The rural revitalization strategy is formulated according to the needs of the county's current economic and social development. This is a requirement to achive the objective, which is comprehensive construction of a substancial society in the new era. The implementation of the rural revitalization strategy should be based on the principle of balanced rural development, which coordinates all aspects of the policy support to rapidly develop the rural economy. The key to implementing rural revitalization is to promote the citys' economic development by prioritizing rural economic growth. Therefore, enforcing rural revitalization is the central government's major development strategy to solve the "three rural" issues $^{[1]}$. The Chinese Academy of Social Sciences issued the "Report on China's City Economic Development (2018)," pointing out that the country's city economy is developing well, the economic growth rate continues to increase, and the quality of economic development is good. However, the differences between the counties are becoming more obvious and the function of city finance to support economic development is gradually decreasing ${ }^{[2]}$. Based on Linhai City's recent economic status, the city's substandard financial system is resulting in inefficient release of credits from financial instituition and low-quality financial services which needs immediate attention of improvement. The support for the economic development of Linhai City is obviously insufficient. Therefore, under the premise that Linhai City is actively promoting transformation by upgrading and achieving high-quality development also the ways to effectively utilise the financial system as its services play an important role in maintaing a stable economic development in Linhai City. 
2 Demand of Financial Growth in the Economic Development of Linhar City

\subsection{Economic development status of Linhai} City

From 2008 to 2018, the economic development in Linhai cities improved steadily. After 2015, the acceleration of GDP growth rate was followed by the steady growth of the secondary and tertiary industries (Figure 1). According to the "2018 Linhai City National Economic and Social Development Bulletin," ${ }^{[3]}$ the statistics show that in 2018, the city's GDP was 67 billion yuan, excluding the price factor with an increase of $7 \%$ over the previous year. Among them, the growth of primary, secondary and tertiary industries increased by $1.5 \%, 7.9 \%$, and $7.0 \%$, respectively. The industrial structure has been optimized from 7.6: 45.8: 46.6 in 2017 to $6.6: 46.3: 47.1$, showing that the proportion of the tertiary industry has increased. From a per capita perspective, the city's per capita GDP reached 55,712 yuan, which is an increase of $6.7 \%$ over the previous year. The per capita disposable income of urban and rural permanent residents was 51,520 and 27,418 yuan, respectively. The income of urban and rural residents were 1.88 times of the income of people from rural areas, with year-on-year growth of $5.9 \%$ and $6.4 \%$ respectively. The comprehensive economic strength of the city was ranked $45^{\text {th }}$ among the top 100 counties in China, and the top 100 investment potential city. In 2017, the Linhai Municipal Government started to implement the rural revitalization strategy by vigorously promoting the integration and development of the secondary and tertiary industries along with the accelerated transformation, upgrading of traditional agriculture and policy support.

\subsection{Demand of financial growth toward the economic development of Linhai cities}

The implementation of the rural revitalization strategy has further increased the financial demand in the economic development of the city which requires an urgent necessity of sufficent funds from city finance. Based on the strategy of rural revitalization, financial institutions invested a large amount of funds in rural areas and allocated more financial resources to rural areas. The overall number of rural financial institutions has continued to rise. Banks and other financial institutions have increased the high-rise demand for loans from various customers. The city's various financial institutions have continued to develop, allowing the rate of deposits and loans of banking financial institutions to increase significantly. It can be seen from Table 1 that from 2015 to 2018, the loan balance of financial institutions in Linhai City and the year-end deposit balance continued to increase, indicating that financial demand has also continued to increase. More farmers are meeting their financial needs through deposits and loans. The implementation of rural revitalization strategies leads to a steady economic growth where the increase in the diversity of businesses being carried out, causing the people's demand for finances also to increase. This positive result of various loans being balanced from multiple financial institues continues to increase.

Under the strategy of rural revitalization, the banks of Linhai City have launched a "big visit" for financial services to the real economy, through accurate understanding of corporate credit needs, publicizing financial business knowledge, developing comprehensive financial services, and optimizing financial service methods. For example, Linhai Rural Commercial Bank issued in 2013 the "Three-year Action Plan for Inclusive Finance" based on the channel which functions in existing service outlets, further optimizing the configuration and using the advantages of outlets to enhance inclusive finance in urban and rural financial services. Similarly, focusing on solving the financial needs of small- and medium-sized enterprises and various agriculture-related businesses, as well as realizing "inclusive entrepreneurship, convenience, and optimism." 
3. Differences between the City's Financial System Arrangements and Needs

\subsection{Insufficient financial institutions in Linhai City}

From 2015 to 2018 Linhai City's financial instituitions have shown that an increase of deposited balance in renminbi (RMB) from 70.765 billion yuan to 92.718 billion yuan, with an average annual growth rate of $12.33 \%$. The balance of RMB loans from financial institutions increased from 59.59 billion yuan to 76.054 billion yuan. The average growth rate was $12.46 \%$. Especially in 2017 and 2018, there was a significant increase in short-term loans. Although the necessity of medium and long-term loans decreased, the overall growth has been relatively stable.

Table 1. Various year-end loan and deposit balances of financial institutions in Linhai City (unit: 100 million yuan)

\begin{tabular}{lllll}
\hline Year-end financial institution balances & 2015 & 2016 & 2017 & 2018 \\
\hline Various loans & 606.68 & 669.90 & 760.54 & 897.91 \\
\hline Various deposits & 707.65 & 837.72 & 927.18 & 1065.34 \\
\hline
\end{tabular}

Data source: Linhai Statistical Yearbook

Table 2. Linhai Rural Commercial Bank's year-end loan balance and agriculture-related loan balance (unit: 100 million yuan)

\begin{tabular}{lllll}
\hline & 2015 & 2016 & 2017 & 2018 \\
\hline Year-end various loan balance & 443.04 & 523.46 & 577.63 & 632.1 \\
\hline Agricultural loans balance & 103.93 & 123.15 & 137.39 & 151.28 \\
\hline
\end{tabular}

Data source: Linhai Rural Commercial Bank's annual information disclosure report.

Table 3. Deposits and loans of financial institutions in Linhai City (unit: 100 million yuan)

\begin{tabular}{lllll}
\hline & 2015 & 2016 & 2017 & 2018 \\
\hline Various deposit balances & 707.65 & 837.72 & 927.18 & 1052.2 \\
\hline Various loan balances & 595.93 & 669.9 & 760.54 & 888.98 \\
\hline Deposit ratio & $84.20 \%$ & $80.00 \%$ & $82.03 \%$ & $84.49 \%$ \\
\hline Short-term loan balance & $9.00 \%$ & $5.50 \%$ & $12.40 \%$ & $17.70 \%$ \\
\hline Medium and long-term loan balance & $16.80 \%$ & $19.60 \%$ & $18.40 \%$ & $13.90 \%$ \\
\hline
\end{tabular}

Data source: Linhai City Statistical Yearbook

\subsection{Prominent contradiction between supply and demand of rural industry insurance}

Linhai City is located in the southeast coast of Taizhou, China where the development of many rural industries such as agriculture and tourism are vulnerable to natural disasters such as typhoons due to its geological factors. For instance, the typhoon "Lichma" that hit Taizhou in 2019 had drastic and severe repercussions on Linhai; 24,931 hectares of crops were destroyed, causing 2.1 billion yuan in economic losses and almost all of the local famous spring tangerines were damaged. As far as 
insurance institutions are concerned, the profitseeking pursuit of business operations by insurance institutions will reduce business insurance premium for rural revitalization industries as there has been problems such as low returns, high risks, and high odds. Financial instituitions have enforced stricter risk assessments for rural industries due to the lack of industrial insurance. In addition, the unwillingness to undertake credit risk exposure reduces its financial support for rural industries ${ }^{[4]}$. Moreover, rural households generally have fewer items available for mortgage which is not conducive to the development of rural revitalization.

\subsection{Low availability of formal credit}

Limited by geographical factors, it is difficult to establish a complete credit investigation system in rural areas. Since rural residents participate in fewer financial activities and lacked in credit history, thus it would affect their credit granted to a certain extent. At the same time, the social credit concept in rural areas is weak. Therefore, there may be norms of arbitrary defaulting of loans or even speculative failure to repay loans. This would lead to the amplification of credit risk of financial institutions which will greatly affect the city's financial system too.

Considering the weakness of rural industries and the under developed rural financial market, agriculture-related investments generally have long cycles, high risks, and low returns on investments ${ }^{[5]}$. Commercial finance is more unwilling to meet rural financial needs, making the government to invest more funds in areas that commercial finance institutions do not want to involve. This kind of fiscal subsidy policy excessively replaces financial support policies, which is not conducive to guiding commercial finance to bear the responsibility of supporting rural revitalization. Also, government subsidies for expenditures cannot make up for the funding gap for rural industrial development, affecting the city economic development under rural revitalization.

\section{Policy Recommendations or the Construction of Linhai City Financial System under Rural Revitalization Strategy}

\subsection{Coordinated development of a multi-level financial market system}

The steady growth of rural economy and the rural revitalization must be implemented in coordinated manner with the development of a multi-level financial market system $^{[6]}$. With the goal of companies listing and equity transfer, the government should strengthen services in the process of enterprise development. The cultivation and guidance of companies are to be listed for effectively promoting more companies to raise funds in the capital market. Among the 24 existing banking financial institutions in Linhai, there is a lack of emerging financial institutions such as nonbanking financial institutions, funds and trust companies, foreign banks as well as internet finance companies. The development pattern of financial industry is yet to be structured.

Therefore, the government needs to speed up in the implementation of the rural credit inclusive financial projects. This is to guide rural commercial banks to rapidly reform and promote the construction of rural commercial banks in remote branches to become the backbone of rural finance. In addition, standardizing the development of small loan companies allows the exploration of highquality small loan companies to issue bonds and conduct business in rural areas. The increase in rural financial business of non-banking financial organizations and introduce more special loans with large quotas with low interest rates for rural areas.

\subsection{Increase of the structural matching between the financial system and the rural economy}

A financial system cannot be built simply by increasing the number of financial institutions; most importantly, these institutions should be matched to the local economic structure ${ }^{[7]}$. We should build a multi-level, extensive rural financial system to increase the integration of commercial 
banks, urban commercial banks and the rural economy. This improves rural financial services, increases the proportion of rural small and mediumsized loans and effectively increases the financial support for the rural economy.

It is necessary to strategically build a government-bank-enterprise cooperation platform to promote its integration with local rural industries in accordance with the strategy of rural revitalization. This supports rural industries through policy guidance and agriculture-related loans. To strengthen cooperations with various banking institutions, the goverment plays an important to innovate relevant rural special financial projects with banking institutions and encourage banking financial institutions to innovate financial products. At the same time, financially support the preferential norm of financial institutions, adopt subsidy measures for financial institutions, set up special incentive funds, and increase the proportion of agricultural loans. Moreover, promoting the online model of financial "Internet +," initially integrates with offline businesses to establish an e-village and purchase mobile service vehicles, so that residents can enjoy services without leaving the village or at their doorstep.

\subsection{Evaluation index system of the city's financial stability through the establishment of the improved rural credit system}

To promote the development of rural finance, it is also necessary to build a complete rural credit system to essentially solve the problem of unreliable rural finances. Since blood relations and geography are still the core of relationships, thus its the most effective way to collect residents information in rural areas. By actively cooperating with rural credit cooperatives, small loan companies and other financial institutions increase their utilization of existing data through field trips to the countryside. They collect basic information of residents, and evaluate the financial information for credit ratings of rural residents through big data analysis. In order to stimulate the participation of residents, the government can evaluate the credit users system to bring the credit indicators into an annual assessment system of villages and towns. Furthermore, building a rural credit information service platform that integrates information such as industry, commerce, finance, social security, taxation, justice, etc., by using a "database plus network" technology, allows to collect and share platform information. This is used to build an effective mobile system credit platform, so that the government and financial institutions can share as well as update resources in real time .

The city's financial stability is a key factor in promoting economic growth in Linhai. It is also one of the most important foundations for Linhai city's rural revitalization strategy. A stabilized financial system should have an evaluation index system and a properly structured rural credit system to speed up the collection of city financial stability evaluation indicators. Then, the information of informal banking financial institutions (including small loan companies, private lending, etc.) should be incorporated into the city financial stability evaluation index system, and use big data platform to update, analyze and evaluate in real time ${ }^{[8]}$. At the same time, formulate relevant rules and regulations to establish a cross-system and join supervision of big digital platforms to ensure the scientific and reasonable financial data are accurate and reliable outcomes.

\subsection{Increased innovation in rural financial products}

To establish a financial system under rural revitalization, a medium like financial products needs to be be provided to show the presents of financial activities. Financial institutions must continue to increase their innovation in financial products to solve the problems of poor compliance and adaptability of many financial products which are in use by local policies and industries. These innovations can start from expanding the variety of financial products, prioritizing local conditions for 
new financial products, and nongshangtong (online trading platfrom for agri-businesses).

Furthermore, by strengthening the communication and understanding of enterprises, the information gap can be voided for industrial and commercial platforms also for farmers. This will help to innovate more novel microfinance models and personalized special products for services. In addition to the original mortgage and pledge loan modes, new loan plans such as intellectual property loan, property right loan and mutual guarantee loans between residents and enterprises will be added. To manage these new loan plans, new repayment methods, such as "revolving loan" and "annual review system," will be enforced in collaboration with electronic platform repayment and payment like applications and SMS payments.

\subsection{Providing better financial quality training for rural residents}

Rural residents loans are often limited by financial factors and their lack of financial knowledge. In this case, it is crusial to change residents initial financial norm by providing the residents with more financial knowledge. In addition, the government and financial institutions' agricultural staff may conduct financial activities in the countryside, like drawing cartoons on rural walls, distributing financial information leaflets, providing residents with free course training, setting up financial accounting professional positions for enterprises at low prices, and cooperating with the local village government to purchase financial books for residents to refer too. It is also possible to encourage outstanding residents, especially those who have succeeded in the finance sector to return to their hometowns through certain policies. They may assist to strengthen residents financial literacy and legal awareness, thus creating a good financial environment.

\section{Disclosure statement}

The author declares no conflict of interest.

\section{References}

[1]National Development and Reform Commission. (2016). Research on the Integration and Development of My Country's Rural Primary, Secondary and Tertiary Industries. Economic Research Reference, (4): 3-28.

[2]LV FY, CHOU LH. (2019). China City Economic Development Report In 2018. Beijing: China Social Sciences Press.

[3]Linhai Municipal Government Website. (2019). Statistical Bulletin of National Economic and Social Development of Linhai City in 2018. http://www.ahmhxc.com/tongjigongbao/13829_2. html.

[4]WANG LJ, KOU GZ. (2017). Several Thoughts on Promoting the Integrated Development of Rural Primary, Secondary and Tertiary İndustries. Issues of Agricultural Economy, (6): 82-88.

[5]WANG B. (2020). Research on the Vulnerability of Traditional Agriculture and Animal Husbandry and Credit Risk Control— Taking Hulunbuir as an Example. Northern Finance. (3):59-62.

[6]HU M. (2015). Research on the Coordinated Development of Agricultural İnsurance and Agricultural Credit in Hunan Province. Central South University of Forestry and Technology.

[7]ZHANG XP, ZHU TH. (2014). Reflection on the Relationship between the Financial System and the Real Economy. International Finance Research, (3):43-54.

[8]XU GX, GUO JN, CHEN RP. (2017). The Construction of China's Financial Stability İndex and its Leading Ability Analysis. Statistics and Information Forum, (4): 27-33 